\title{
Fast food consumption and obesity risk among university students of Bangladesh
}

\author{
Shatabdi Goon ${ }^{1}$, Munmun Shabnam Bipasha ${ }^{2}$, Md. Saiful Islam ${ }^{3}$ \\ ${ }^{1}$ Nutrition and Food Engineering Department, Daffodil International University, Dhaka -1207, Bangladesh \\ ${ }^{2}$ Department of Economics, Daffodil International University, Dhaka, Bangladesh \\ ${ }^{3}$ Dietician, VLCC Health Care, Bangladesh \\ Email address: \\ shatabdigoon@yahoo.com (S. Goon)
}

\section{To cite this article:}

Shatabdi Goon, Munmun Shabnam Bipasha, Md. Saiful Islam. Fast Food Consumption and Obesity Risk among University Students of Bangladesh. European Journal of Preventive Medicine. Vol. 2, No. 6, 2014, pp. 99-104. doi: 10.11648/j.ejpm.20140206.14

\begin{abstract}
Fast food consumption leading to excess calorie intake coupled with lack of adequate physical activity has increased the risk of obesity among the world population for the past few decades. A cross-sectional study was carried out from March to April 2014 among four hundred twenty six students selected by the use of systematic random sampling attending in an established private university of Bangladesh. The objective of this study was evaluating fast food consumption and prevalence of obesity among university students. The overall prevalence of fast food consumption was $55.9 \%$ and $44.1 \%$ for males and females, respectively. Approximately 56\% of university students went to fast food restaurants at least once per week and $44 \%$ went regularly ( $\geq 2$ times/wk). Status of obesity was found to be significantly associated with frequenting fast-food restaurants; students going two or more times per week were more likely to be obese (OR 2.2; 95\% CI 1.3-3.9). Obesity was detected among $56.2 \%$ of those students going two or more times per week in fast food restaurants showed significantly high prevalence $\left(\mathrm{X}^{2}=7.82, \mathrm{p}<0.05\right)$. This study provides evidence of increasing trend in obesity among university students consuming fast foods regularly. A combined initiative from family, universities, public health experts and government is much needed to tackle this public health problem.
\end{abstract}

Keywords: Fast Food, Obesity, University Students, Bangladesh

\section{Introduction}

Obesity accounts for approximately 300,000 deaths a year in the United States, and prevalence rates have been increasing over the past decade. 1 In 2010, 43 million children (35 million in developing countries) were estimated to be overweight and obese; 92 million were at risk of overweight. 2 More than 9 million U.S. children and youth are obese and another 15 percent are at risk for becoming obese. 3 The consequential health risks of obesity among adolescents include asthma, hypertension, type 2 diabetes, cardiovascular disease, depression and excess mortality in adulthood 4,5 Several data suggest that inappropriate dietary practices (fast food consumption, low fruit consumption), low physical activity, spending time on sedentary activities such as watching television and playing video games, low parental education, and family history of obesity are risk factors for adolescents overweight and obesity. 6

Among the behavioral factors, fast food consumption exerted the largest influence on higher levels of obesity.7 Fast food, usually sold at eating establishments for quick availability or takeout 8 has been become popular among young population in recent years. Increases in fast food consumption among young adults may contribute to increasing obesity rates worldwide to become a global concern 9-12, as excessive consumption during the transition to adulthood is associated with increased weight gain from adolescence to adulthood.13 Most cross-sectional studies that have examined the association between fast food consumption combined with increasing portion sizes and decreased physical activity and measures of obesity in children and adolescents has been implicated as a potential contributing factor in the obesity crisis.14-19 Increasing rates of obesity and overweight have been linked to the rising energy density of the diet.20 Fast food dense with high calorie, high saturated and trans fat and sugar and lacking of 
fibers can result in excessive weight gain both in adolescents and adults. A nationally representative survey on children and adolescents in USA showed that, participants who ate fast food, compared with those who did not, consumed more total energy (187 kcal; 95\% confidence interval [CI]: 109$265)$, more energy per gram of food $(0.29 \mathrm{kcal} / \mathrm{g} ; 95 \% \mathrm{CI}$ : 0.25-0.33), more total fat (9 g; 95\% CI: 5.0-13.0), more total carbohydrate $(24 \mathrm{~g} ; 95 \% \mathrm{CI}: 12.6-35.4)$, more added sugars (26 g; 95\% CI: 18.2-34.6), more sugar-sweetened beverages (228 g; 95\% CI: 184-272), less fiber $(-1.1 \mathrm{~g} ; 95 \% \mathrm{CI}:-1.8$ to -0.4 ), less milk (-65 g; 95\% CI: -95 to -30 ), and fewer fruits and nonstarchy vegetables $(-45 \mathrm{~g} ; 95 \% \mathrm{CI}$ : -58.6 to -31.4$)$. 21 Another cross-sectional study showed that adults and children who reported eating fast food had higher intake of energy, fat, saturated fat, sodium, carbonated soft drink, and lower intake of vitamins $\mathrm{A}$ and $\mathrm{C}$, milk, fruits and vegetables than those who did not reported eating fast food $(\mathrm{P}<.001) .22$ In a Cross-sectional study, it was observed that, fast food consumption was positively associated with BMI and higher consumption of fast food at year 7 was associated with a 0.16-unit higher BMI at year 10.23 Children and adolescents consuming greater quantities of fast food are generally heavier, have greater total energy intakes, and have poorer diet quality. In a cross-sectional analyses, adjusting for potential confounders, mean (SE) BMI was 19.1 (0.13) among children who ate fast food "never or $<1$ /week," 19.2 (0.13) among those who responded "1 to 3 times/week," and 19.3 (0.18) among those who responded, "4 to 7 times/week.24 The frequency of consuming restaurant food is positively associated with increased body fatness in population.25,26A telephone survey of 1033 Minnesota residents reported a positive association between increased frequency of fast food consumption and BMI. 27 In a survey, after 3 years observation, it was reported that, increases in frequency of fast food restaurant use were associated with increases in body weight and total energy intake. 28

In Bangladesh, paradoxically coexisted with malnutrition among children and adolescents, multiple factors such as rapid urbanization, inappropriate dietary practices, continually decreasing number of playgrounds, probably have lead to less physical and more sedentary activity, and thereby have attributed to an emerging overweight and obesity problem among young children in urban settings, especially among affluent families in Dhaka.29 University students are taking fast foods both occasionally and regularly and therefore, facing obesity and related health complications, resulting increased health care cost. The objective of this study was to determine the prevalence of obesity among university students who excessively consume fast foods.

\section{Methodology}

A cross-sectional study was carried out from March to April, 2014 among students attending in one established private university of Bangladesh located at Dhanmondi, Dhaka: Daffodil International University. A total number of
426 university students within age 18 to 24 were selected by use of systematic random sampling selecting every $2^{\text {nd }}$ students attending that established private university. Considering an expected result prevalence of $50 \%$ and using a confidence level of $95 \%$ the sample size of the cross sectional study was calculated as 426. Students who were there in university campus during the survey period were included in the study and those who were not regular in that sense were excluded from the study. Equal number of male and female students was selected for the interview. All of the selected students were made well informed of the study aims and verbal consent was taken for their participation in the study. Interviews were conducted in the classroom, varsity canteen while they were enjoying their class break. A semistructured questionnaire was used to collect data regarding age, sex, meal pattern, fast-food preference, fast food consumption per week, soft drinks preference, cause behind fast food access, time preferred for fast food consumption etc. In the cross sectional study, weight and height status were observed as baseline.

\section{Study Design}

Questionnaire and some technical procedures were encountered as study instruments. The majority of the demographic information was collected by face-to-face interview. Body mass index (BMI) $\left(\mathrm{kg} / \mathrm{m}^{2}\right)$ was calculated based on clinically assessed weight $(\mathrm{kg})$ and height $(\mathrm{m})$ at baseline. The current analysis considered only the baseline measurements, as there was no notable change with regard to BMI during the follow up across the trials. WHO definitions were used to categorize students as normal weight (BMI: 18.5-24.9), overweight (BMI: 25-29.9) and obese (BMI: 30 and above). Weight and height was measured by pre-defined procedure using weight machine and measuring tap.

\section{Anthropometric Assessment}

Weight and height were measured to evaluate the BMI (body mass index). Body mass index (BMI) is a simple index of weight-for-height that is commonly used to classify overweight and obesity in adults. A BMI greater than or equal to 25 is overweight and a BMI greater than or equal to 30 is obesity. Ranges from 18.5 to 24.9 of BMI ensure the normal level. The problem with using BMI as a body weight categorization tool, is that it does not take into account bony structure, muscle mass or percentages of lean mass compared to adipose tissue. At best, Body Mass Index is a crude measure of health. However, academic literature that analyzes weight status typically uses BMI as a primary indicator for study group categorization.

\section{Statistical Analysis}

SPSS 15.0 version was used for statistical analyzes. Descriptive statistics including mean, standard deviation were obtained. All analysis was done with the test of 
significance ( $p$ value, Chi-square).

\section{Result and Data Analysis}

This paper represents the prevalence of fast food consumption and obesity risk determined by body mass index (BMI) among Bangladeshi university students. A total number of 426 students attending an established private university were interviewed and examined. The mean age of the selected university students was $21.3 \pm 5.38($ Mean $\pm \mathrm{SD}$ ).

The overall prevalence of fast food consumption was $55.9 \%$ and $44.1 \%$ for males and females, respectively. Approximately $56 \%$ of university students went to fast food restaurants at least once per week and $44 \%$ went regularly ( $\geq 2$ times/wk). Among respondents who reported going to fast-food restaurants at least once per week, the reason for choosing this type of restaurant was that it was quick and convenient $(41.9 \%)$, followed by taste of the food (30.6\%), sociability, and its good value in terms of cost [Table 1]

$73(31.8 \%)$ and $89(38.9 \%)$ students consuming fast foods were reported as obese and overweight with BMI of $>30 \mathrm{~kg} / \mathrm{m} 2$ and $>25 \mathrm{~kg} / \mathrm{m} 2$ respectively. $58 \quad(25.3 \%)$ students hold the normal body weight with BMI of 18.5-24.9 $\mathrm{Kg} / \mathrm{m} \mathrm{2}$. Results showed that majority of the fast food consumers were overweight [Table 2]. The prevalence of obesity increased consistently with frequenting fast-food restaurants, from $43.8 \%$ of those going less than once a week to $56.2 \%$ of those going 2 or more times per week.[Table 3]

Intensity of the correlation between frequency of fast food consumption and BMI level was found significantly in Table 4. In this study, statistically highly significant correlation $(\mathrm{P}=0.01)$ between frequency of consumption and BMI level were established. Positive correlation between the frequency of consumption and BMI was established. [Table 4]

Unadjusted odd ratio for frequency of fast food consumption by BMI Category of obesity was established in this study. Obesity was found to be significantly associated with frequency of fast food consumption; students going two or more times per week were more likely to be obese (OR 2.2; 95\% CI 1.3-3.9). [Table 5]

Obesity was detected among $56.2 \%$ of those students going two or more times per week in fast food restaurants showed significantly high prevalence $(\mathrm{X} 2=7.82$, $\mathrm{p}<0.05)$. [Table 6]

\section{Discussion}

The main finding of this study was determined by the prevalence of fast food consumption and risk of obesity among Bangladeshi university students. The results of this study are very alarming with an epidemic of obesity in those university students, consuming fast foods. Around thirty-nine percent (39\%) students, taking fast foods were identified as overweight where around thirty two percent $(32 \%)$ were recorded as obese with different stages of obesity. Beth Anderson and his colleagues showed the overall prevalence of fast food consumption with $28 \%{ }^{12}$ studying on Michigan adults, where present study shows the prevalence of fast food consumption among young adults with $53.8 \%$. Another cross sectional study among northeast Ohio residents showed the prevalence of fast food consumption with $42 \%{ }^{30}$, where this current findings shows an increased prevalence in Bangladesh. In another survey, it was reported that, approximately $63 \%$ respondents took fast food at least once in a week ${ }^{31}$, where this present data supports the result with around $54 \%$. Another survey showed that, at least one in four adults reported eating fast food ${ }^{32}$, where this study shows at least 2 in four respondents reported taking fast food.

Study conducted by Islam \& Ullah $^{33}$ identified brand reputation, accessibility, taste, cost, quality, food hygiene, and fat and cholesterol level as the factors related to fast food preferences by the university students in Bangladesh. In this study, it was also reported convenience, easy accessibility, taste, cost as the factors related to fast food preference among Bangladeshi university students. In this study, the main reason that Bangladeshi university students go to fast food restaurants that they are convenient and quick (41.9\%). Similar results have been reported in a study that, Michigan adults go to fast-food restaurants is that they are quick and convenient $(64 \%)^{12}$ too. In another study, results have been reported by Rydell et al ${ }^{34}$, using data from a convenience sample of adolescents and adults in the Minneapolis/St. Paul, Minnesota, metropolitan area. Limited time, good taste, eating with friends and family, and cost were the most prevalent reasons among a sample of college students from a large Midwestern university ${ }^{35}$.

Fast food, although it is convenient and a tasty addition to a diet, can have serious health and social effects. Regular eating of fast food can increase the risk of weight gain and obesity in adolescents and adults having energy density with presence of high levels of fat and sugar of the meal, corresponding low level of fiber and protein apparently. Fraser LK and his colleagues showed that, the consumption of fast food was associated with a higher BMI SD score ( $\beta=0.08,95 \% \mathrm{CI}=0.03,0.14$ ); higher body fat percentage $(\beta=2.06,95 \% \mathrm{CI}=1.33,2.79)$; and increased odds of being obese $(\mathrm{OR}=1.23,95 \% \mathrm{CI}=1.02,1.49)^{11}$, where this current data also suggests an increased odds of being obese (OR 2.2; 95\% CI 1.3-3.9) among those students taking fast foods regularly. Another study showed that, the teenagers who ate at fast food restaurants consumed more unhealthy foods and were more likely to have higher BMI than those teenagers who did not eat frequently at Fast food restaurants. ${ }^{34}$ Similarly, this study also shows a high prevalence of obesity among fast food consumers with $31.8 \%$. The prevalence of obesity increased consistently with frequenting fast-food restaurants. A cross sectional study among Michigan adults showed that, prevalence of obesity increased with frequenting fast food restaurants from $24 \%$ of those going less than once a week to $33 \%$ of those going 3 or more times per week. ${ }^{12}$ The present study also reports increased prevalence of obesity from $43.8 \%$ of those going less than once a week to $56.2 \%$ of those going 2 or more times per 
week. Another study among European students showed that, fast-food consumption was a risk factor for obesity (odds ratio: $2.27 ; 95 \%$ CI 1.08 to 4.77$)^{36}$, where this study also supports the data with odd ratios (OR 2.2; 95\% CI 1.3-3.9) among those students taking fast foods regularly. In a study, the odds of being obese were approximately 50\% higher among those consuming fast-food 2 or more times per week compared with those consuming it less than once per week. ${ }^{12}$ The results of this study also showed that prevalence of obesity was twice among students consuming fast food more than two days per week compared to those consumed once in a week.

In this study, statistically highly significant correlation ( $P=0.01$ ) between frequency of consumption and BMI level were established. Positive correlation between the frequency of consumption and BMI was established. Unadjusted odd ratio for frequency of fast food consumption by BMI Category of obesity was established in this study. Obesity was found to be significantly associated with frequency of fast food consumption; students going two or more times per week were more likely to be obese (OR 2.2; 95\% CI 1.3-3.9). Obesity was detected among $56.2 \%$ of those students going two or more times per week in fast food restaurants showed significantly high prevalence $\left(\mathrm{X}^{2}=7.82, \mathrm{p}<0.05\right)$.

It was indicated through this study that most of the fast food users are well known about negative effects associated with fast food consumption. However, they were reported to have fast food at regular basis without considering their health complications. The young generations are getting addicted to fast food that indicates a serious public health concern and urgent actions should be taken to tackle this public health problem.

Our study has a number of limitations. The data were selfreported and the study is cross-sectional which does not infer causal relationships. Furthermore, we examined only one private university in the Capital city; caution should be taken to generalize the data for public universities or universities outside Dhaka city.

\section{Conclusion}

This paper reports fast food preference and food habits associated with obesity risk among students attending universities of Bangladesh. It is recognized that prevention is the most feasible option for curbing the obesity epidemic since current treatment practices are largely aimed at bringing the problem under control rather than affecting a cure. Learning life-long habits that incorporate exercise and healthy eating are essential and research is emerging regarding various methods of educating youth with a view to control the epidemic.

\section{Acknowledgement}

We would like to thanks our honorable professors, colleagues and friends for supporting us to initiate the study subject. We are also grateful to those students who cooperated with us to conduct the interview.

Table 1. Habits and patterns of food consumption of the respondents

\begin{tabular}{ll}
\hline Characteristics/food habits & Respondents (\%) \\
\hline Gender & $213(50 \%)$ \\
Male & $213(50 \%)$ \\
Female & \\
Fast food consumption & $229(53.8 \%)$ \\
Yes & $197(46.2 \%)$ \\
No & \\
Fast food consumption by sex & $128(55.9 \%)$ \\
Male & $101(44.1 \%)$ \\
Female & \\
Fast food consumption (day/wk) (n-229) & $131(57.2 \%)$ \\
1 day/week & $98(42.8 \%)$ \\
$\geq 2$ day/week & \\
Reasons of fast food preference (n-229) & $96(41.9 \%)$ \\
Convenience & $70(30.6 \%)$ \\
Taste/pleasure & $31(13.5 \%)$ \\
Influenced by others & $27(11.8 \%)$ \\
Lack of other suitable option & $5(2.2 \%)$ \\
Pocket friendly(comparatively cheap) &
\end{tabular}

Table 2. Distribution of fast food consumers by their BMI level

\begin{tabular}{lllll}
\hline Total & Underweight & Normal(Healthy weight) & Overweight & Obesity \\
\hline 229 & $9(4 \%)$ & $58(25.3 \%)$ & $89(38.9 \%)$ & $73(31.8 \%)$ \\
\hline
\end{tabular}

Table 3. Distribution of obese respondents by fast food consumption frequency

\begin{tabular}{llc}
\hline \multirow{2}{*}{ Total obese } & \multicolumn{2}{l}{ Frequency of Fast Food Consumption } \\
\cline { 2 - 3 } & $\mathbf{1}$ day/week & $\geq 2$ days/week \\
\hline 73 & $32(43.8 \%)$ & $41(56.2 \%)$ \\
\hline
\end{tabular}

Table 4. Data of correlation strength between frequency of fast food consumption (FFC) and BMI level of respondents

\begin{tabular}{lll}
\hline Variables & Frequency of FFC & BMI level \\
\hline Frequency of FFC & 1 & $.572^{* *} 0.00$ \\
$\mathrm{~N}$ & 229 & 229 \\
$\mathrm{BMI}$ & $.572^{* *} 0.00$ & 1 \\
$\mathrm{~N}$ & 229 & 229 \\
\hline
\end{tabular}

** Significance $P=0.01$ level (2-tailed) 
Table 5. Unadjusted OR for frequency of fast food consumption (FFC) by BMI Category of obesity

\begin{tabular}{llll}
\hline & Total & Obese BMI $>\mathbf{3 0} \mathbf{~ k g} / \mathbf{m}^{\mathbf{2}}$ & \\
\hline Frequency of FFC & & $\mathrm{n}$ & OR $(95 \% \mathrm{CI})$ \\
$\geq 2$ days/week & 41 & 41 & $2.2 ; 1.3-3.9$ \\
\hline
\end{tabular}

Table 6. Distribution of fast food consumers according to the presence or absence of specific weight status (obesity)

\begin{tabular}{lllll}
\hline Character & Present/absent & \multicolumn{1}{l}{ Frequency of fast-food consumption } & Statistical values \\
\hline \multirow{4}{*}{ Obesity } & & 1 day $/$ week & $\geq 2$ days $/$ week & \\
& Present & $32(43.8 \%)$ & $41(56.2 \%)$ & $\mathrm{X}^{2}=7.82, \mathrm{p}<0.05$ \\
\hline
\end{tabular}

\section{References}

[1] Maddock J. The relationship between obesity and the prevalence of fast food restaurants: state-level analysis. Am J Health Promot. 2004 Nov-Dec;19(2):137-43.

[2] de Onis M, Blossner M, Borghi E: Global prevalence and trends of overweight and obesity among preschool children. Am J Clin Nutr 2010, 92:1257-1264.

[3] McGinnis JM, Gootman JA, Kraak VI. Food Marketing to Children and Youth: Threat or Opportunity? Washington DC: National Academies Press; 2006

[4] Maffeis C1, Tatò L. Long-term effects of childhood obesity on morbidity and mortality. Horm Res. 2001;55 Suppl 1:42-5.

[5] Francis DK1, Van den Broeck J, Younger N, McFarlane S, Rudder K, Gordon-Strachan G,et al. Fast-food and sweetened beverage consumption: association with overweight and high waist circumference in adolescents. Public Health Nutr. 2009 Aug;12(8):1106-14. doi: 10.1017/S1368980009004960. Epub 2009 Feb 26.

[6] Singh AK, Maheshwari A, Sharma N, Anand K: Lifestyle associated risk factors in adolescents. Indian J Pediatr 2006, 73:901-906.

[7] Garcia G1, Sunil TS, Hinojosa P.The fast food and obesity link: consumption patterns and severity of obesity. Obes Surg. 2012 May;22(5):810-8. doi: 10.1007/s11695-012-0601-8.

[8] U.S. Department of Agriculture, U.S. Department of Health and Human Services. Dietary guidelines for Americans, 2010. 7th ed. Washington, DC: U.S. Government Printing Office. 2010 .

[9] R W Jeffery and S A French. Epidemic obesity in the United States: are fast foods and television viewing contributing? American Journal of Public Health. Feb 1998, 88(2):277-280.

[10] Garcia G1, Sunil TS, Hinojosa P. The fast food and obesity link: consumption patterns and severity of obesity. Obes Surg. 2012 May;22(5):810-8. doi: 10.1007/s11695-012-0601-8.

[11] Fraser LK1, Clarke GP, Cade JE, Edwards KL. Fast food and obesity: a spatial analysis in a large United Kingdom population of children aged 13-15. Am J Prev Med. 2012 May;42(5):e77-85. doi: 10.1016/j.amepre.2012.02.007.

[12] Anderson B1, Rafferty AP, Lyon-Callo S, Fussman C, Imes G. Fast-food consumption and obesity among Michigan adults. Prev Chronic Dis. 2011 Jul;8(4):A71. Epub 2011 Jun 15.

[13] Niemeier HM1, Raynor HA, Lloyd-Richardson EE, Rogers
ML, Wing RR. Fast food consumption and breakfast skipping: predictors of weight gain from adolescence to adulthood in a nationally representative sample. J Adolesc Health. 2006 Dec;39(6):842-9. Epub 2006 Sep 27.

[14] Schröder H1, Fïto M, Covas MI; REGICOR investigators. Association of fast food consumption with energy intake, diet quality, body mass index and the risk of obesity in a representative Mediterranean population. Br J Nutr. 2007 Dec;98(6):1274-80. Epub 2007 Jul 12.

[15] Fraser LK1, Edwards KL, Cade JE, Clarke GP. Fast food and obesity: a spatial analysis in a large United Kingdom population of children aged 13-15. Am J Prev Med. 2012 May;42(5):e77-85. doi: 10.1016/j.amepre.2012.02.007.

[16] Satia JA1, Galanko JA, Siega-Riz AM. Eating at fast-food restaurants is associated with dietary intake, demographic, psychosocial and behavioural factors among African Americans in North Carolina. Public Health Nutr. 2004 Dec;7(8):1089-96.

[17] Fleischhacker SE1, Evenson KR, Rodriguez DA, Ammerman AS. A systematic review of fast food access studies. Obes Rev. 2011 May;12(5):e460-71. doi: 10.1111/j.1467789X.2010.00715.x.

[18] Bowman SA1, Vinyard BT. Fast food consumption of U.S. adults: impact on energy and nutrient intakes and overweight status. J Am Coll Nutr. 2004 Apr;23(2):163-8.

[19] Ryan T. Hurt, MD, PhD, Christopher Kulisek, MD, Laura A. Buchanan, MD, and Stephen A. McClave. The Obesity Epidemic: Challenges, Health Initiatives, and Implications for Gastroenterologists. Gastroenterol Hepatol (N Y). Dec 2010; 6(12): 780-792.

[20] Mendoza JA1, Drewnowski A, Cheadle A, Christakis DA. Dietary energy density is associated with selected predictors of obesity in U.S. Children. J Nutr. 2006 May;136(5):1318-22.

[21] Bowman SA1, Gortmaker SL, Ebbeling CB, Pereira MA, Ludwig DS. Effects of fast-food consumption on energy intake and diet quality among children in a national household survey. Pediatrics. 2004 Jan;113(1 Pt 1):112-8.

[22] Paeratakul S, Ferdinand DP, Champagne CM, Ryan DH, Bray GA. Fast-food consumption among US adults and children: dietary and nutrient intake profile. J Am Diet Assoc. 2003 Oct;103(10):1332-8.

[23] Duffey KJ1, Gordon-Larsen P, Jacobs DR Jr, Williams OD, Popkin BM. Differential associations of fast food and restaurant food consumption with 3-y change in body mass index: the Coronary Artery Risk Development in Young Adults Study. Am J Clin Nutr. 2007 Jan;85(1):201-8. 
[24] Taveras EM1, Berkey CS, Rifas-Shiman SL, Ludwig DS, Rockett HR, Field AE,et_al. Association of consumption of fried food away from home with body mass index and diet quality in older children and adolescents. Pediatrics. 2005 Oct;116(4):e518-24.

[25] McCrory MA1, Fuss PJ, Hays NP, Vinken AG, Greenberg AS, Roberts SB. Overeating in America: association between restaurant food consumption and body fatness in healthy adult men and women ages 19 to 80. Obes Res. 1999 Nov;7(6):56471

[26] Larson N1, Neumark-Sztainer D, Laska MN, Story M. Young adults and eating away from home: associations with dietary intake patterns and weight status differ by choice of restaurant J Am Diet Assoc. 2011 Nov;111(11):1696-703. doi: 10.1016/j.jada.2011.08.007.

[27] Robert W Jeffery,囚1 Judy Baxter,1 Maureen McGuire,2 and Jennifer Linde1 Are fast food restaurants an environmental risk factor for obesity? Int J Behav Nutr Phys Act. 2006; 3: 2.

[28] French SA1, Harnack L, Jeffery RW. Fast food restaurant use among women in the Pound of Prevention study: dietary, behavioral and demographic correlates. Int $\mathrm{J}$ Obes Relat Metab Disord. 2000 Oct;24(10):1353-9.

[29] Ahmed SMM, Islam MS, Razzaque A, Ahmed T: Socioeconomic differentials of childhood obesity among school children in the context of affluent society of Dhaka City. In 11th Annual Conference (Scientific ASCON). Dhaka, Bangaldesh: icddr,b; 2007:129.
[30] Butt S1, Leon JB, David CL, Chang H, Sidhu S, Sehgal AR. The prevalence and nutritional implications of fast food consumption among patients receiving hemodialysis. J Ren Nutr. 2007 Jul;17(4):264-8.

[31] Latetia V. Moore, Ana V. Diez Roux, Jennifer A. Nettleton, David R. Jacobs, and Manuel Franco. Fast-Food Consumption, Diet Quality, and Neighborhood Exposure to Fast Food. Am J Epidemiol. Jul 1, 2009; 170(1): 29-36.

[32] Bowman SA, Vinyard BT.Fast food consumption of U.S. adults: impact on energy and nutrient intakes and overweight status. J Am Coll Nutr. 2004 Apr;23(2):163-8.

[33] Islam N, Ullah GMS. Factors affecting consumers' preferences on fast food items in Bangladesh. J Applied Business Research 2010; 26:131-46.

[34] Rydell SA, Harnack LJ, Oakes JM, Story M, Jeffery RW, French SA. Why eat at fast-food restaurants: reported reasons among frequent consumers. $\mathrm{J}$ Am Diet Assoc. 2008;108(12):2066-2070

[35] Morse KL, Driskell JA. Observed sex differences in fast-food consumption and nutrition self-assessments and beliefs of college students. Nutr Res. 2009;29(3):173-179.

[36] Fraser LK1, Edwards KL, Cade JE, Clarke GP. Fast food, other food choices and body mass index in teenagers in the United Kingdom (ALSPAC): a structural equation modelling approach. Int J Obes (Lond). 2011 Oct;35(10):1325-30. doi: 10.1038/ijo.2011.120. Epub 2011 Jun 28. 